\title{
Optical coherence tomography in patients undergoing cataract surgery
}

\author{
Tomografia de coerência óptica em pacientes submetidos a cirurgia de catarata
}

Carlos Augusto Moreira Neto ${ }^{1}$, Carlos Augusto Moreira Júnior², Ana Tereza Ramos Moreira ${ }^{2}$

\begin{abstract}
Purpose: To assess the ability of spectral domain optical coherence tomography (SD-OCT) to diagnose macular changes pre- and post-cataract surgery and to identify changes in central foveal thickness (CFT) relative to age, sex, and presence of concomitant ophthalmic pathologies, for a period of 6 months post-surgery.

Methods: A prospective study of patients evaluated by SD-OCT within $5 \mathrm{~h}$ before surgery at 7, 30,60, 90, and 180 days post-op, with respect to CFT and presence of maculopathy.

Results: Ninety-eight eyes of 98 patients were evaluated, with the following mean results: age $=71.4$ years, pre-op VA $=0.27 \log M A R$, and final $V A=0.73$ $\log$ MAR. There were 21 eyes in patients with diabetes mellitus (DM) and 10 eyes with age-related macular degeneration (AMD), three with epiretinal membrane, and four with glaucoma. Sixty eyes had no other ophthalmic-related pathologies (NOO), and had a mean pre-op CFT of $222 \mu \mathrm{m}$, which progressively increased up to the $60^{\text {th }}$ day post-op, reaching a mean of $227.2 \mu \mathrm{m}$. No pseudophakic cystoid macular edema was observed. The mean CFT was statistically significantly different $(p<0.001)$ between $\mathrm{NOO}$ and diabetic patients from 30 days post-op. Four eyes presented with preoperative diagnosis of AMD as measured by ophthalmoscopy After completion of the OCT, which was performed within $5 \mathrm{~h}$ before surgery, six additional patients were found to have AMD. Of the 98 total eyes, 10 were diagnosed with maculopathy only by OCT exam. Binocular indirect ophthalmoscopy (BIO) was unable to detect such changes.

Conclusion: OCT diagnosed preoperative maculopathies in $21.4 \%$ of the patients, and was more effective than $\mathrm{BIO}(11.2 \%)$. OCT showed a progressive increase in CFT in diabetics up to 180 days post-operatively, as well as greater CFT in male patients and patients older than 70 years.
\end{abstract}

Keywords: Cataract extraction; Fovea centralis; Diabetes mellitus; Tomography, optical coherence; Visual acuity

\section{RESUMO}

Objetivos: Avaliar a capacidade da tomografia ocular de coerência de domínio espectral Spectral Domain-Optical Coherence Tomography (SD-OCT) diagnosticar alterações maculares no pré e pós-operatório da cirurgia de catarata e a variação da espessura foveal central (CFT) de acordo com a idade, sexo, presença ou não de oftalmopatias associadas, pelo período de 6 meses após a cirurgia.

Método: Estudo prospectivo com pacientes avaliados pela SD/FD-OCT no pré-operatório (dia da cirurgia) e 7, 30, 60, 90 e 180 dias após, no que se refere à EFC e presença de maculopatia.

Resultados: Foram avaliados 98 olhos de 98 pacientes, 35 homens e 63 mulheres. O estudo mostrou a seguintes médias: idade $=71,4$ anos, AV pré-operatória $=0,27$, AV final $=0,73$. Vinte-um olhos eram de pacientes com diabetes mellitus (DM), 10 apresentavam degeneração macular relacionada à idade (AMD), 3 com membrana epirretiniana e 4 tinham glaucoma. Sessenta olhos apresentavam-senormais, ou seja, sem outras oftalmopatias (NOO). Avaliando a EFC do grupo NOO observou-se uma CFT média no pré-operatório de $222 \mu \mathrm{m}$, que mostrou um aumento progressivo até o 60 dia de pós-operatório, quando atingiu média de 227,2 $\mu$ m. Não foi observado edema macular cistóide do pseudofácicos. Ao comparar a diferença entre a CFT média de pacientes NOO e pacientes diabéticos, observou-se que os valores são significativos $(p<0,001)$ a partir do 30 - dia de pós-operatório. Quatro olhos apresentaram, pela oftalmoscopia, diagnóstico pré-operatório de DMRI. Após a realização do exame de $O C T$, horas antes da cirurgia, observou-se que mais 6 pacientes apresentavam AMD. Do total de 98 olhos, 10 tiveram o diagnóstico de maculopatia somente pelo exame de OCT. A oftalmoscopia binocular indireta (BIO) não foicapaz de detectar tais alterações. Conclusão: $O$ OCT diagnosticou doenças maculares pré-operatórias em 21,4\% dos pacientes, sendo mais efetivo que a BIO $(11,2 \%)$. Mostrou um aumento progressivo da CFT em diabéticos até 180 dias de pós-operatório. Detectou que a CFT é maior em pacientes do sexo masculino, e que a CFT dos pacientes com mais de 70 anos é maior que em pacientes mais jovens.

Descritores: Extração de catarata; Fóvea central; Diabetes mellitus; Tomografia de coerência óptica; Acuidade visual

\section{INTRODUCTION}

The outcome of cataract surgery is based on the technical quality of the procedure and the presence of other ophthalmic diseases or complications before, during, and after surgery.

To identify the potential visual acuity (VA) to be achieved following surgery, and to identify other diseases that can affect the final result, various tests can be performed depending on the clinical situation at hand, such as the measurement of potential VA and the use of binocular indirect ophthalmoscopy (BIO), etc. Among other currently available ancillary exams for retinal evaluation, optical coherence tomography (OCT) is the least invasive exam offering the most information on the macula ${ }^{(1)}$.

OCT technology allows for observation of the retinal structures (ganglion cells, nerve fiber layer, photoreceptors), including the optic disc and fovea, and thus provides important diagnostic information for accurate evaluation of the macular area ${ }^{(2)}$.

The current study evaluates the ability of spectral domain optical coherence tomography (SD-OCT) to detect pre- and postoperative
Submitted for publication: February 2, 2015

Accepted for publication: May 5, 2015

Hospital de Olhos do Paraná, Curitiba, PR, Brazil.

${ }^{2}$ Department of Ophthalmology, Universidade Federal do Paraná (UFPR), Curitiba, PR, Brazil.
Funding: No specific financial support was available for this study.

Disclosure of potential conflicts of interest: None of the authors have any potential conflict of interest to disclose.

Corresponding author: Carlos A. Moreira Neto. Rua Fernando Simas, 1.010 - Curitiba - PR - 80710660 - Brazil - E-mail: moreiraguto@hotmail.com

Approved by the following research ethics committee: Federal University of Paraná (UFPR), 654.007. 
macular alterations, as well as the variation in the central foveal thickness (CFT) in patients undergoing cataract surgery, and correlates these findings with age, sex, and the presence or absence of concomitant ophthalmic pathologies.

\section{METHODS}

This study was approved by the Federal University of Paraná Research Ethics Committee, and only included patients with a diagnosis of senile cataract who had not previously undergone eye surgery and who attended all follow-up exams. All patients signed an informed consent form. This prospective, analytical, observational, longitudinal study included patients of the Unified Health System scheduled for phacoemulsification and intraocular lens (IOL) implantation.

Preoperative evaluation included VA (logMAR), refraction, biomicroscopy, applanation tonometry, and BIO. The same evaluation was repeated postoperatively at 1,30 , and 180 days. The OCT exam was performed on all patients using a Spectralis OCT (Heidelberg Engineering $\mathrm{GmbH}$, Heidelberg, Germany) within $5 \mathrm{~h}$ preoperatively and postoperatively at 7,30,60,90, and 180 days.

All patients were preoperatively administered tropicamide $1 \%$, moxifloxacin $5 \mathrm{mg} / \mathrm{ml}$, and diclofenac sodium $0.1 \%$, with postoperative administration of moxifloxacin hydrochloride $5.45 \mathrm{mg} / \mathrm{ml} \mathrm{com-}$ bined with disodium phosphate dexamethasone $1.10 \mathrm{mg} / \mathrm{ml}$ and ketorolac tromethamine $0.4 \%$. All surgeries were performed by experienced surgeons.

The results were evaluated in their totality and further analyzed in groups according to age, sex, and with reference to any concomitant pathologies.

To compare the groups with respect to the CFT variable, profile analysis was employed. The repeated measures model (ANOVA) was used to compare patients with no other ophthalmic-related pathologies (NOO). The nonparametric Mann-Whitney test was used to compare the groups defined by atrophic and exudative AMD, and assessment of the homogeneity of variance was performed using Levene's test. $P$ values of $<0.05$ were considered statistically significant. Data were analyzed using the computer program SPSS v.20.0 (IBM Corporation, Armonk, NY, USA).

\section{RESULTS}

We evaluated 98 eyes of 98 patients (63 females). There were no intraoperative complications, and all IOLs were implanted in the capsular sac. The patients' ages ranged from 43 to 90 years, with a mean of 71.4 years. The initial and final mean logMAR VA were 0.6 and 0.1 , respectively.

Sixty of the 98 eyes evaluated (61.2\%) presented with NOO, 21 (21.4\%) were patients with diabetes mellitus (DM), 10 (10.2\%) presented age-related macular degeneration (AMD), three (3.1\%) presented epiretinal membrane (ERM), and four (4.1\%) presented glaucoma associated with cataract.

In the 60 NOO eyes, the mean pre- and postoperative logMAR VA were 0.6 and 0.1 , respectively, which were statistically significantly different $(p<0.001)$. As shown by OCT, the mean pre-op CFT of $222 \mu \mathrm{m}$ progressively increased up to 60 days postoperatively, when it reached a mean of $227.2 \mu \mathrm{m}(p<0.001)$. Thereafter, the CFT decreased through to the final OCT examination, when it reached a mean of $224.9 \mu \mathrm{m}$ (Figure 1). Neither cystoid macular edema (CME) nor Irvine-Gass Syndrome were observed. Similar CFT values were observed in the four eyes with glaucoma associated with cataracts.

The 21 eyes of the DM patients presented mean pre- and postoperative VA of 0.5 and 0.1 , respectively. Starting from the 30th day post-operatively, the mean CFT was statistically significantly different between the NOO and diabetic patients $(p<0.001)$ (Figure 1), suggesting a difference in the progression of the DM and $\mathrm{NOO}$ cases in terms of the CFT. Unlike in the patients with NOO pathologies, there was a progressive increase in the mean CFT from the preoperative OCT examination $(222.6 \mu \mathrm{m})$ to the final exam $(253.3 \mu \mathrm{m})$.

The preoperative $\mathrm{BIO}$ exam showed that among the 21 eyes of patients with DM, 14 had no ophthalmoscopic signs of diabetic retinopathy (DR), and seven were categorized as eyes with mild nonproliferative diabetic retinopathy (NPDR).

However, in the preoperative OCT examination, one of the 14 eyes that was clinically defined as not having DR was actually found to have mild DR. Of the seven eyes with clinical signs of DR, the preoperative OCT exam showed that three had mild NPDR and four had moderate NPDR. Still, none had macular edema (ME) as assessed by OCT. After 180 days of follow-up, three eyes without DR progressed into mild NPDR without ME, and two eyes with moderate NPDR without ME progressed into moderate DR with ME (Table 1).

Four eyes presented with a clinical diagnosis of AMD using $\mathrm{BIO}$ (one atrophic, three exudative). The preoperative OCT exam identified four additional patients with atrophic AMD and two with exudative AMD. Table 2 shows the distribution of patients with AMD according to pre-and postoperative VA scores. The CFT scores of both types of AMD were also evaluated. The subset of eyes with atrophic AMD showed low variation in CFT, reaching maximum values on the $7^{\text {th }}$ day post-op (mean $=181.25 \mu \mathrm{m}$ ), while the subset with exudative AMD reached the maximum CFT on the 30th day post-op (mean = 386.25 $\mu \mathrm{m}$ ) (Figure 2).

We also compared the VA and CFT scores between male and female NOO patients; no significant difference was found between the sexes. Table 3 shows that male patients had a higher mean CFT than female patients at all time points, with statistical significance.

The VA and CFT scores were also compared between patients 70 years and younger and patients over 70 years. The mean pre- and postoperative VA scores differed very little between the two groups,

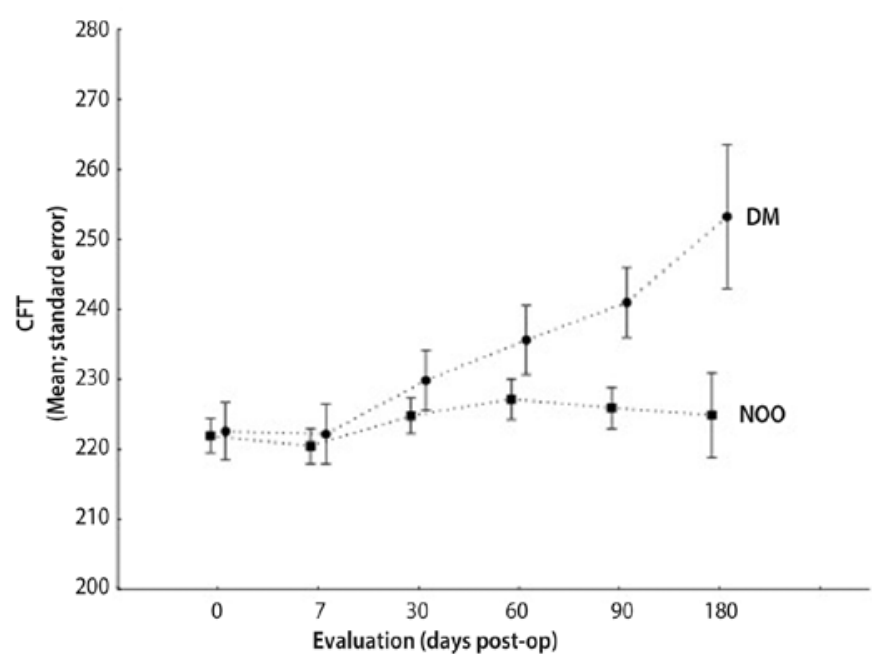

Figure 1. Distribution of central foveal thickness (CFT) in microns, by postoperative days in the diabetes mellitus (DM) and no other ophthalmic-related pathologies (NOO) groups.

Table 1. Distribution of eyes in patients with diabetes mellitus by DR classification* and time (days) of follow-up

\begin{tabular}{lccccc}
\hline & $\begin{array}{c}\text { Without } \\
\text { DR }\end{array}$ & $\begin{array}{c}\text { Mild NPDR } \\
\text { w/o ME }\end{array}$ & $\begin{array}{c}\text { Moderate } \\
\text { NPDR w/o ME }\end{array}$ & $\begin{array}{c}\text { Moderate } \\
\text { NPDR w/ ME }\end{array}$ & Total \\
\hline Preoperative & 13 & 4 & 4 & 0 & 21 \\
Postoperative & 10 & 7 & 2 & 2 & 21 \\
(180 days) & & & & & \\
\hline
\end{tabular}

$\mathrm{DR}=$ diabetic retinopathy; $\mathrm{NPDR}=$ nonproliferative diabetic retinopathy; $\mathrm{w} / \mathrm{o}=$ without; $\mathrm{w} /=$ with; $\mathrm{ME}=$ macular edema.

${ }^{*}=$ International clinical diabetic retinopathy and diabetic macular edema disease severity scales. 
while the mean CFT in the group aged 70 years or younger was lower than in the group over 70 years in all follow-up tests. In terms of the CFT variable, the progression of cases in patients 70 years and younger was statistically significantly different than in patients over 70 years $(p=0.016)$.

Three eyes had preoperative ERM that was only detected after the OCT exam. The first case showed no improvement of VA with cataract surgery, with a preoperative CFT of $196 \mu \mathrm{m}$ and a 180-day post-operatively CFT of $179 \mu \mathrm{m}$. The second case had a pre- and postoperative VA of 0.1 and 0.3 , respectively. The preoperative CFT was $614 \mu \mathrm{m}$, and the final CFT was $606 \mu \mathrm{m}$. Unlike the two previous cases, the third patient had a preoperative VA of 0.3 and CFT of $424 \mu \mathrm{m}$, and postoperative VA of 1.0 and CFT of $449 \mu \mathrm{m}$.

Of the 98 eyes, OCT preoperatively diagnosed macular disease in 21 eyes (21.4\%), while BIO diagnosed maculopathies in just 11 (11.2\%).

\section{DISCUSSION}

The inclusion of OCT exams as part of the routine preoperative tests for intraocular surgeries is imminent, driven by its noninvasive nature and greater accuracy in the diagnosis of macular diseases. Additionally, as this equipment becomes more popular, it will subsequently become less costly. Compared to other tests used for the

Table 2. Distribution of eyes of patients by VA (logMAR) and type of age-related macular degeneration

\begin{tabular}{lccc}
\hline Group & Pre-operative VA & Post-operative VA & Difference \\
\hline Dry $(n=5)$ & $0.76 \pm 0.40$ & $0.70 \pm 0.30$ & $-0.58 \pm 0.37$ \\
Wet $(n=5)$ & $0.94 \pm 0.38$ & $0.64 \pm 0.50$ & $-0.30 \pm 0.27$ \\
P value* & 0.548 & 0.095 & 0.309 \\
\hline
\end{tabular}

$V A=$ visual acuity; ${ }^{*}=$ nonparametric Mann-Whitney test, $p<0.05$.

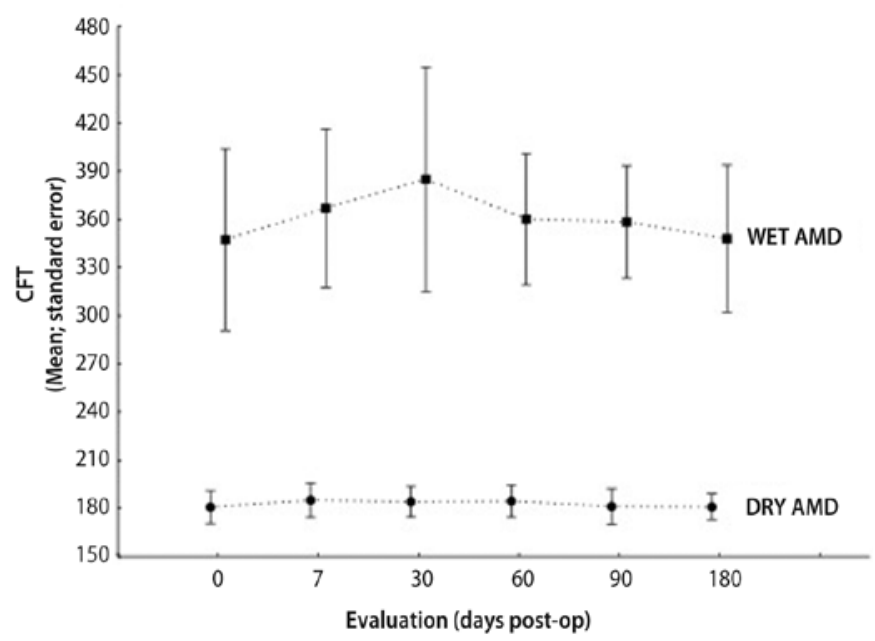

Figure 2. Distribution of central foveal thickness (CFT) in micrometers, by postoperative days and type of age-related macular degeneration (AMD). diagnosis of macular diseases, such as retinal angiography or electroretinography, OCT is not only safer, it is more precise and practical.

In the present study, the preoperative $\mathrm{BIO}$ exam detected macular alterations in 11 eyes (11.2\%): seven with DR and four with AMD. In addition to those 11 eyes with $\mathrm{BIO}$-detected macular changes, OCT revealed 10 additional eyes with maculopathies (six AMD, one mild NPRD, and three ERM), with a total of 21 eyes (21.4\%). In addition to greater accuracy during preoperative evaluation, OCT also allowed for detailed monitoring of the macula in the postoperative period, thus revealing the reason for the worsening vision in some eyes, especially in diabetic patients.

The difference observed between the $\mathrm{BIO}$ examination and OCT may be due to the inaccuracy of the pre-op BIO examination performed by the clinician, who is not a retinal specialist and may not have noticed the subtle macular changes, especially when lens opacification is present. On the other hand, seeing a retina specialist is not routine as part of the preoperative examination for cataract surgery. Therefore, the findings presented here may be very similar to what happens in the real world of ophthalmic practice. Additionally, the near-infrared light in OCT allows for more precise observation of the retina.

Besides the diagnostic capabilities of OCT, the measurements of retinal thickness, especially the CFT, are important in the follow-up of operated eyes. In our study, a progressive increase was observed in the CFT of the NOO group from the 7th to the 60th day after surgery, which then began decreasing up to the 180th day post-op, when the values approximated those obtained in the preoperative examination. However, male patients showed a decreased CFT only 180 days after surgery, whereas female patients showed a decrease in CFT values from the 90th day post-operatively.

Similarly, Corrêa et al. ${ }^{(2)}$ evaluated the CFT of 62 eyes with no other associated pathologies by SD-OCT at pre-op, 1 week, and 1 month following cataract surgery, and observed a continuous increase in the CFT until 30 days post-operatively.

The incidence of clinically significant CME is 0.6-2.6\%; however, the incidence of subclinical CME is uncertain ${ }^{(3,4)}$. Using OCT, Bélair et al. ${ }^{(5)}$ showed that the incidence of CME in patients without other eye pathologies was $4 \%$ and $0 \%$ at 30 and 60 days post-operatively, respectively. However, there was no statistically significant difference between the two evaluated time points.

Other studies showed that the incidence of subclinical CME diagnosed by OCT varies between $0-22 \%{ }^{(4,6,7)}$. No cases of subclinical CME or Irvine-Gass syndrome were observed in our study. The discrepancy in the incidence of subclinical CME can be explained by variations in the inclusion and exclusion criteria, and by different medication protocols employed in the postoperative period of different studies ${ }^{(6)}$.

Among the 21 eyes in patients with DM, who underwent phacoemulsification in the present study, seven presented signs of DR via preoperative $\mathrm{BIO}$ exams. Preoperative OCT not only found that one eye thought to be without NPDR actually had mild NPDR, but also helped to better classify the remaining seven eyes with DR (three with NPDR and four with mild-to-moderate NPDR without ME). OCT also showed that after 180 days post-op, three eyes without DR developed mild NPDR without ME, and two eyes with moderate NPDR without ME developed moderate DR with ME.

Table 3. Distribution of mean CFT $(\mu \mathrm{m})$ in patients with no other ophthalmopathies by follow-up length (days) and sex

\begin{tabular}{|c|c|c|c|c|c|c|}
\hline Group & CFT 0 & CFT 7 & CFT 30 & CFT 60 & CFT 90 & CFT 180 \\
\hline Female $(n=41)$ & $219.8 \pm 14.9$ & $217.5 \pm 14.9$ & $221.5 \pm 15.2$ & $224.2 \pm 17.7$ & $221.7 \pm 16.2$ & $220.6 \pm 15.8$ \\
\hline Male $(n=19)$ & $226.7 \pm 24.9$ & $227.2 \pm 25.1$ & $232.1 \pm 26.5$ & $233.7 \pm 27.3$ & $235.2 \pm 26$ & $234.2 \pm 26.4$ \\
\hline$P$ value* & 0.017 & 0.012 & 0.009 & 0.037 & 0.020 & 0.022 \\
\hline
\end{tabular}

CFT = central foveal thickness; ${ }^{*}=$ Levene's test. 
Cataract surgery has the potential to induce inflammatory and mechanical changes in vitreoretinal structures, thus causing macular thickening with changes to $\mathrm{VA}^{(8)}$, probably due to damage to the blood-retinal barrier(9,10).

Jun et al. ${ }^{(11)}$ evaluated 637 OCT exams (Stratus) in patients with macular diseases and CFT scores less than $252 \mu \mathrm{m}$. They found that $25 \%$ of the patients had NPDR. Although $75 \%$ of the patients with diabetes had clinical reports of ME, their OCTs were normal on the day of examination. While this finding can be explained by therapeutic factors, only one patient underwent laser photocoagulation in the 3 months preceding the study. Thus, diabetic patients may have ME with no increase in CFT.

The incidence of ME found via OCT testing is $22 \%$ in the eyes of diabetic patients undergoing cataract surgery ${ }^{(12)}$. On the other hand, DR is known to progress in 10-30\% of patients undergoing phacoemulsification ${ }^{(7,13-16)}$. In these studies, the main factor responsible for the progression of DR was the degree of DR at the time of phacoemulsification ${ }^{(15,17,18)}$.

Previous studies have shown that diabetic ME progresses in 20$40 \%$ of eyes undergoing cataract surgery, although swelling disappears spontaneously in most of these eyes ${ }^{(19-21)}$.

In 2009, Hayashi et al. ${ }^{(22)}$ performed OCT (Stratus) in diabetic patients who underwent cataract surgery with IOL implantation. The final sample was 34 eyes without DR and 34 eyes with DR. The OCT was performed to obtain the CFT 1 day before surgery and 3,6, and 12 months postoperatively. They noted an increase in the CFT in both groups after performing phacoemulsification, although this increase was much more significant in the group with DR, as was also shown in our study.

In another study, Biro et al. ${ }^{(23)}$ compared the CFT of 18 eyes of diabetic patients with 36 eyes of nondiabetic patients using SD-OCT preoperatively and at $1,7,30$, and 60 days post-op, with the contralateral eye acting as the control. Patients with any other ophthalmic pathologies were excluded, as well as those with severe NPDR or with proliferative DR. A significant increase was noted in the CFT in both the groups with DM and without DM as compared with their respective controls. Additionally, there was a significant increase in the CFT in both groups when compared with the preoperative examination, and in the exams on days 7, 30, and 60 post-op. Similar findings were observed in our diabetic patients, who showed a gradual increase in CFT up to the last day of assessment, while the patients with no concomitant eye pathologies had a peak in their CFT 60 days post-op, which was followed by a decline.

In our study, only one patient presented with atrophic AMD and three with exudative AMD, which had all already been clinically diagnosed prior to surgery. In the pre-op OCT exams, four more cases of atrophic AMD and two more cases of exudative AMD were diagnosed, thus showing the importance of the OCT exam as part of the preoperative assessment for cataract surgery. The CFT for the exudative AMD group increased up to the 30th day post-operatively, reaching $386.25 \mu \mathrm{m}$, and subsequently regressed back to their approximate pre-op values. The subset with atrophic AMD had virtually no changes in their CFT, which peaked on day 7 after surgery $(121.25 \mu \mathrm{m})$.

With regard to AMD, the importance of a preoperative OCT exam is even more evident for patients undergoing cataract surgery, since of the 10 patients in our sample, six were diagnosed only after the preoperative OCT. An increase was observed in the CFT for both types of AMD, which peaked on the seventh day after surgery, although this returned to similar values to the preoperative period by the final examination for both types. Clearly, there is a large difference between the CFT values of patients with atrophic and exudative AMD, since they have different clinical courses.

In 2012, Monestam et al. ${ }^{(24)}$ showed that patients with clinical signs of AMD at the time of cataract surgery have a lower gain in vision than patients without AMD symptoms. That said, for patients with AMD, cataract surgery is still beneficial, since the visual result 10 years after surgery is better than preoperative vision. In our study, we observed no statistically significant difference relative to the VA in patients with atrophic or exudative AMD, pre- or postoperatively.

As for CFT in regards to sex, male patients with no other eye pathologies in the present study had higher CFT than females at all evaluation time points $(p<0.05)$. Schuman et al. ${ }^{(25)}$ and Gupta et al. ${ }^{(26)}$ also showed that males present higher CFT values than females.

In this study, patients over the age of 70 years had higher CFT than those 70 years and younger. Both age groups presented an increase in CFT up to 60 days post-op, and thereafter, there was a subsequent decrease up to the final day of follow-up. Therefore, it was statistically shown that the development of cases in patients up to the age of 70 years is different to those over the age of 70 years. In 2013, Gharbiya et al. ${ }^{(6)}$ reported that there was no significant relationship between age and CFT, with $p=0.56$. However, Gupta et al. ${ }^{(26)}$ obtained different results, with older patients presenting a lower CFT, which decreased by $0.38 \mu \mathrm{m}$ per year.

Finally, is important to point out that although OCT examination may offer a better evaluation of fundus changes, showing additional details, it is not a substitute for adequate clinical evaluation made with $\mathrm{BIO}$.

\section{CONCLUSION}

OCT examination was able to diagnose macular diseases during preoperative assessment for phacoemulsification and was more effective than BIO examination. Moreover, OCT evaluated CFT scores in patients with DR, showing a progressive increase up to 180 days postoperatively. It also showed that CFT is higher in males than in females, and in patients aged over 70 years than in those 70 years and younger.

Our results demonstrated that OCT is a reliable and useful preoperative examination for patients undergoing cataract surgery.

\section{REFERENCES}

1. Schuman JS, Puliafito CA, Fujimoto JG, JS Duker JS, editors. Optical coherence tomography of ocular diseases. 3rd ed. Thorofare: US SLACK Inc; 2013.

2. Correa EP, Oliveira LF, Serracarbassa PD, Oshima A, Castro EF. Avaliação do edema macular após a cirurgia não complicada de facoemulsificação com implante de lente intraocular por meio de coerência óptica spectral domain. Arq Bras Oftalmol. 2013; 76(6):357-62.

3. Mentes J, Erakgun T, Afrashi F, Kerci G. Incidence of cystoid macular edema after uncomplicated phacoemulsification. Ophthalmologica. 2003;217(6):408-12.

4. Nicholas S, Riley A, Patel H, Neveldson B, Purdie G, Wells AP. Correlations between optical coherence tomography measurement of macular thickness and visual acuity after cataract extraction. Clin Experiment Ophthalmol. 2006;34(2):124-9;quiz 194.

5. Belair ML, Kim SJ, Thorne JE, Dunn JP, Kedhar SR, Brown DM, et al. Incidence of cystoid macular edema after cataract surgery in patients with and without uveitis using optical coherence tomography. Am J Ophthalmol. 2009;149(1):128-35.

6. Gharbiya M, Cruciani F, Cuozzo G, Parisi F, Russo P, Abdolrahimzadeh S. Macular thickness changes evaluates with spectral domain optical coherence tomography after uncomplicated phacoemulsification. Eye (Lond). 2013;27(5):605-11.

7. Kato S, Fukada Y, Hori S, Tanaka Y, Oshika T. Influence of phacoemulsification and intraocular lens implantation on the course of diabetic retinopathy. J Cataract Refract Surg. 1999;25(6):788-93.

8. Giansanti G, Bitossi A, Giacomelli G, Virgili G, Pieretti G, Giuntoli M, et al. Evaluation of macular thickness after uncomplicated cataract surgery using opyical coherence tomography. Eur J Ophthalmol. 2013;23(5):751-6.

9. Kusbeci T, Eryigit L, Yavas G, Inan UU. Evaluation of cystoid macular edema using optical coherence tomography and fundus fluorescein angiography aftre uncomplicated phacoemulsification surgery. Curr Eye Res. 2012;37(4):327-33.

10. Vinores SA, Amin A, Derevjanik NL, Green WR, Campochiaro PA. Immunohistochemical localization of blood-retinal barrier breakdown sites associated with post-surgical macular oedema. Histochem J. 1994;26(8):655-65.

11. Jun J, Duker JS, Baumal CR, McCabe F, Reichel E, Rogers AH, et al. Cystoid macular edema without macular thickening: A retrospective optical coherence tomography study. Retina. 2010;30(6):917-23.

12. Kim SJ, Equi R, Bressler NM. Analysis of macular edema after cataract surgery in patients with diabetes using optical coherence tomography. Ophthalmology. 2007;114(5): 881-9. 
13. Zaczek A, Olivestedt G, Zetterstrom C. Visual outcome after phacoemulsification and IOL implantation in diabetic patients. Br J Ophthalmol. 1999:83(9):1036-41.

14. Antcliff R, Poulson A, Flanagan DW. Phacoemulsification in diabetics. Eye (Lond) 1996;10(Pt 6):737-41

15. Pollack A, Leiba H, Bukelman A, Abrahami S, Oliver M. The course of diabetic retinopathy following cataract surgery in eyes previously treated by laser photocoagulation. Br J Ophthalmol. 1992;76(4):228-31.

16. Henricsson M, Heijl A, Janzon L. Diabetic retinopathy before and after cataract surgery. Br J Ophthalmol. 1996;80(9):789-93.

17. Pollack A, Dotan S, Oliver M. Progression of diabetic retinopathy after cataract extrac tion. Br J Ophtahlmol. 1991;75(9):547-51.

18. Somaiya MD, Burns JD, Mintz R, Warren RE, Uchida T, Godley BF. Factors affecting visua outcomes after small-incision phacoemulsification in diabetic patients. J Cataract Refract Surg. 2002;28(8):1364-71.

19. Dowler JGF, Sehmi KS, Hykin PG, Hamilton AM. The natural history of macular edema cataract surgery in diabetes. Ophthalmology. 1999;106(4):663-8.

20. Dowler JGF, Hykin PG, Hamilton AMP. Phacoemulsification versus extracapsular cataract extraction in patients with diabetes. Ophthalmology. 2000;107(3):457-62.
21. Squirrell D, Bhola R, Bush J, Winder, Talbot JF. A prospective, case controlled study of the natural history of diabetic retinopathy and maculopathy after uncomplicated phacoemulsification cataract surgery in patients with type 2 diabetes. $\mathrm{Br} J$ Ophthalmol. 2002;86(5):565-71.

22. Hayashi K, Igarashi C, Hirata A, Hayashi H. Changes in diabetic macular oedema after phacoemulsification surgery. Eye (Lond). 2009;23(2):389-96

23. Biró Z, Balla Z. OCT measurements on the foveal and perifoveal retinal thickness on diabetic patients after phacoemulsification and IOL implantation. Eye (Lond). 2010;24(4):639-47.

24. Monestam E, Lundgvist B. Long-term visual outcome after cataract surgery: Comparision of healthy eyes and eyes with age related macular degeneration. J Cataract Refract Surg. 2012;38(3):409-14.

25. Schuman M, Dubis AM, Nordgren RN, Lei Y, Odell D, Chiao H, et al. Race- and sex-related diferences in retinal thickness and foveal pit morphology. Invest Ophthalmol Vis Sci. 2011;52(1):625-34.

26. Gupta P, Sidhartha E, Tham YC, Chua DK, Liao J, Chen CY, et al. Determinants of macular thickness using spectral domain optical coherence tomography in healthy eyes: the Singapore Chinese Eye study. Invest Ophthalmol Vis Sci. 2013:54(13):7968-76.

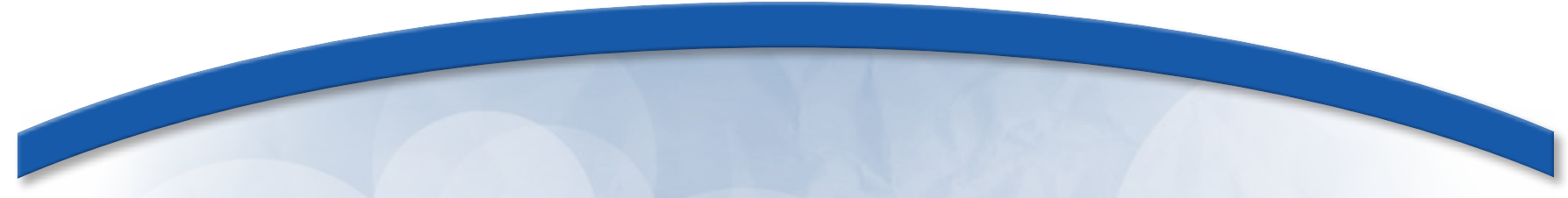

XXXV Congresso do Hospital São Geraldo

29 a 31 de outubro de 2015

Hotel Mercure Lourdes

Belo Horizonte - MG

Informações:

Tel.: (31) 3342-3888

E-mail: lyrium@lyrium.com.br 